\title{
Feature Level Fusion of Iris and Sclera using Entropy Based CNN Features to Improve the Performance of Biometric Authentication
}

\author{
Mrunal Pathak $^{1}$, Dr. Nulaka Srinivasu ${ }^{2}$, Dr. Vinayak Bairagi ${ }^{3}$ \\ ${ }^{1}$ Department of CSE, K. L. University, Guntur, India, mrunalkapathak@ gmail.com \\ ${ }^{2}$ Department of CSE, K. L. University, Guntur, India, srinivasu28@kluniversity.in \\ ${ }^{3}$ Department of E\&TC, AISSM's IOIT, S. P. P. University, Pune, India, vbairagi@ yahoo.co.in
}

\begin{abstract}
Today biometric system are commonly used for person authentication based on physical and behavioral biometric modalities like iris, face, finger prints, ear, sclera, DNA, voice, signature, etc. Instead of using standalone biometric system, multimodal biometric systems are secure and provide more accurate results for person identification and verification. This paper describes the multimodal eye biometric system where iris and sclera features are extracted using $\mathrm{CNN}$ based on entropy values to perform the accurate automatic segmentation. Feature level fusion is performed using color and texture characteristics of iris and pupil with Y-shaped sclera characteristics from eye image based on support value. Unconstrained color eye image database UBIRIS.v2 and MMU are used for experimentation and testing on MATLAB platform. The proposed eye biometric system outperform in case of segmentation and recognition accuracy. Segmentation accuracy $97.8 \%$ for iris, $98.1 \%$ for sclera and $99.4 \%$ for pupil is achieved for UBIRIS.v2 database. Recognition accuracy is $97.99 \%$ for unconstrained eye image UBIRIS.v2 and $93.33 \%$ for NIR image database MMU.
\end{abstract}

Key words: entropy value, Multimodal, support value, unimodal.

\section{INTRODUCTION}

Traditional human identification systems are based on password, PIN, cards, etc. which are not reliable because it can be forgotten, lost or stolen [1]. Therefore there is demand for more secure authentication system which uses unique and persistent characteristics of person that cannot be forgotten easily [2]. Biometric systems are classified as unimodal/standalone and multimodal biometric system. Unimodal biometric system uses single biometric modality such as iris, face, fingerprint, sclera, voice, signature etc. for person identification. Accuracy of unimodal biometric system is reduced because of the challenges such as noisy data, non universality, inter-intra class variation, spoofing attacks. These challenges are overcome by multimodal biometric system in which two or more different types of characteristics of either same biometric trait or features from different biometric trait are combined together to provide more accurate and reliable recognition results [3]-[5].

From literature among all the biometric iris provide the higher authentication accuracy. But success of iris recognition is depends upon the image acquisition and user cooperation. Performance of iris recognition degrades for color eye images acquired in non ideal case without user cooperation because of noisy, motion blur, off angle and illuminated images [6]. Multimodal eye biometric system can be provide solution to overcome these challenges in iris recognition by combining iris features with other eye biometric trait such as retina, sclera, conjunctival vasculature, cornea to improve recognition accuracy. Research in multimodal eye biometric such as ocular and peri-ocular biometric has been growing today due to ease of use in different nosy condition [7].

Proposed system represents the eye biometric system based on the content based image retrieval approach [30] for the fusion of iris, sclera and pupil features to improve the authentication for non ideal color eye images. Entropy values are estimated based on best quality features extracted from image such as color, brightness and texture to reduce the computational cost. These entropy values are used to classify iris, sclera and pupil region automatically using convolutional neural network $(\mathrm{CNN})$ to get better the segmentation result and also reduce the segmentation error rate and time [8]. Multi-algorithmic feature extraction is applied to extract prominent features from segmented image which are combined together based on feature level fusion to calculate support value [9]. 
Table 1: Summary of ocular and periocular biometric fusion approach in eye biometric

\begin{tabular}{|c|c|c|c|c|c|}
\hline Author & Multu-Biometric & Methodology & Type Of Fusion & Database & Result \\
\hline $\begin{array}{l}\text { Zhi Zhou et.al. } \\
{[11]}\end{array}$ & Iris+Sclera & $\begin{array}{l}\text { 1-D Log-Gabor } \\
\text { filter }\end{array}$ & $\begin{array}{l}\text { Quality based } \\
\text { Match score level }\end{array}$ & UBIRIS & $\begin{array}{l}\text { FAR is } 94.92 \% \text { to } \\
96.42 \%\end{array}$ \\
\hline $\begin{array}{l}\text { Vikas } \\
\text { Gottemukkula } \\
\text { et.al.[12] }\end{array}$ & $\begin{array}{l}\text { Iris + Conjunctival } \\
\text { Vasculature }\end{array}$ & $\begin{array}{l}\text { 1-D Log-Gabor } \\
\text { filter }\end{array}$ & $\begin{array}{l}\text { weighted fusion } \\
\text { with mach score }\end{array}$ & In-house database & EER of $2.83 \%$ \\
\hline $\begin{array}{l}\text { Chun-Wei Tan } \\
\text { and Ajay Kumar } \\
{[13]}\end{array}$ & Iris+ Periocular & $\begin{array}{l}\text { random walker } \\
\text { algorithm }\end{array}$ & $\begin{array}{l}\text { Match score level } \\
\text { fusion }\end{array}$ & $\begin{array}{l}\text { UBIRIS.v2, FRGC and } \\
\text { CASIA.v4 }\end{array}$ & $\begin{array}{l}52.4 \% \text { in rank-one } \\
\text { recognition accuracy }\end{array}$ \\
\hline $\begin{array}{l}\text { Jibu Varghese K } \\
\text { et.al. [14] }\end{array}$ & Iris+Sclera & $\begin{array}{l}\text { Otsu's threshold } \\
\text { method and Gabor } \\
\text { filter }\end{array}$ & $\begin{array}{l}\text { Individual Iris and } \\
\text { sclrea recognition }\end{array}$ & In-house database & Accuracy $=99.45 \%$ \\
\hline $\begin{array}{l}\text { C. Immaculate } \\
\text { Mary [15] }\end{array}$ & Iris+Sclera & $\begin{array}{l}\text { Least Mean } \\
\text { Square(LMS) } \\
\text { filtering } \\
\end{array}$ & $\begin{array}{l}\text { Interfusion of Iris } \\
\text { and Sclera surface } \\
\text { using Laplace }\end{array}$ & Q-FIRE & Accuracy $=85 \%$ \\
\hline $\begin{array}{l}\text { Gil Santos et.al. } \\
{[16]}\end{array}$ & Iris+ periocular & $\begin{array}{l}\text { SIFT \&GIST and } \\
\text { 2D gabor wavelet }\end{array}$ & score level fusion & CSIP database & $\begin{array}{l}\text { EER from } 0.145 \% \text { to } \\
2.331 \%\end{array}$ \\
\hline $\begin{array}{l}\text { Nassima Kihal } \\
\text { et.al.[17] }\end{array}$ & $\begin{array}{l}\text { iris and corneal } \\
\text { shape }\end{array}$ & $\begin{array}{l}\text { Zernike polynomial } \\
\text { expansion,LDA and } \\
\text { Gabour Filter }\end{array}$ & $\begin{array}{l}\text { Match score level } \\
\text { fusion }\end{array}$ & In-House database & $\begin{array}{l}\text { EER equal to } 0 \% \\
\text { and a FRR }=0 \% \text { at } 0.1 \% \\
\text { FAR }\end{array}$ \\
\hline $\begin{array}{l}\text { Mrunal Pathak, } \\
\text { et.al. [18] }\end{array}$ & Iris+Sclera & $\begin{array}{l}\text { GLCM,Gabor } \\
\text { wavelet }\end{array}$ & $\begin{array}{l}\text { Match score level } \\
\text { fusion }\end{array}$ & UBIRIS V2 & $\mathrm{EER}=2.31 \%$ \\
\hline $\begin{array}{l}\text { Nasir U. Ahmed } \\
\text { et.al.[19] }\end{array}$ & Iris+ periocular & $\begin{array}{l}\text { Multi-Block } \\
\text { Transitional Local } \\
\text { Binary Pattern } \\
\end{array}$ & score level fusion & MICHE & EER $=1.22 \%$ \\
\hline $\begin{array}{l}\text { Zi Wang et.al. } \\
{[20]}\end{array}$ & eye region & $\begin{array}{l}\text { mixed convolutional } \\
\text { and residual } \\
\text { network } \\
\text { (MiCoReNet) }\end{array}$ & $1--$ & $\begin{array}{l}\text { CASIA-Iris-IntervalV4 } \\
\text { and the UBIRIS.v2 }\end{array}$ & $\begin{array}{l}\text { Accuracy for } \\
\text { CASIA-Iris-IntervalV4= } \\
99.08 \% \text { and } \\
\text { UBIRIS.v2 }=96.12 \%\end{array}$ \\
\hline
\end{tabular}

Authentication is performed by matching support value match score with template stored value in database using Euclidean distance.

\section{RELATED WORK}

Recently eye biometric is explored to improve the biometric recognition results in non ideal scenario because of availability of prominent and stable features among each individual such as color and texture features presented in iris as well as sclera. Eye biometric can be categorized as ocular and periocular biometric system. Ocular biometric refers to combine biometric trait such as iris, sclera, pupil, retina, conjunctival vasculature features which are present inside the eye region whereas periocular refers to features from surrounding eye region [10]. In paper [11],[18], iris and sclera texture features are combined together using match score level fusion for good quality images only. Paper [12] describes multimodal biometric system based on match score level weighted fusion of iris and conjunctival vascular texture features. In paper [13] ,individual iris and sclera recognition is performed simultaneously using Otsu's threshold method and Gabor filter which is experimented only for frontal images. Iris and sclera surface feature's inter fusion is proposed in paper [14]-[15] using least mean square filtering method. Eye biometric system by combining iris and periocular features are described based on score level fusion for noisy eye images in paper [16]. [18]-[19] to reduce the equal error rate. In paper [16], eye biometric authentication is presented based on complete eye region using deep learning method.

\section{PROPOSED EYE BIOMETRIC SYSTEM}

This section elaborate on different phases of proposed multimodal eye biometric system such as image preprocessing, segmentation of iris ,sclera and pupil region using convolutional neural network(CNN $\}$ based on entropy values, multialgorithmic feature extraction, feature level fusion and matching.

\subsection{Preprocessing}

The objective of preprocessing is to enhance the input image by suppressing the unwanted distortion. At first stage, input image is taken from the database which is converted from 
RGB image to gray image to minimize the computational complexity. Furthermore min-max normalization is used to perform linear transformation on input image to fit the data in specific range. Next, the non linear bilateral filtering is used for smoothing purpose by preserving edges.

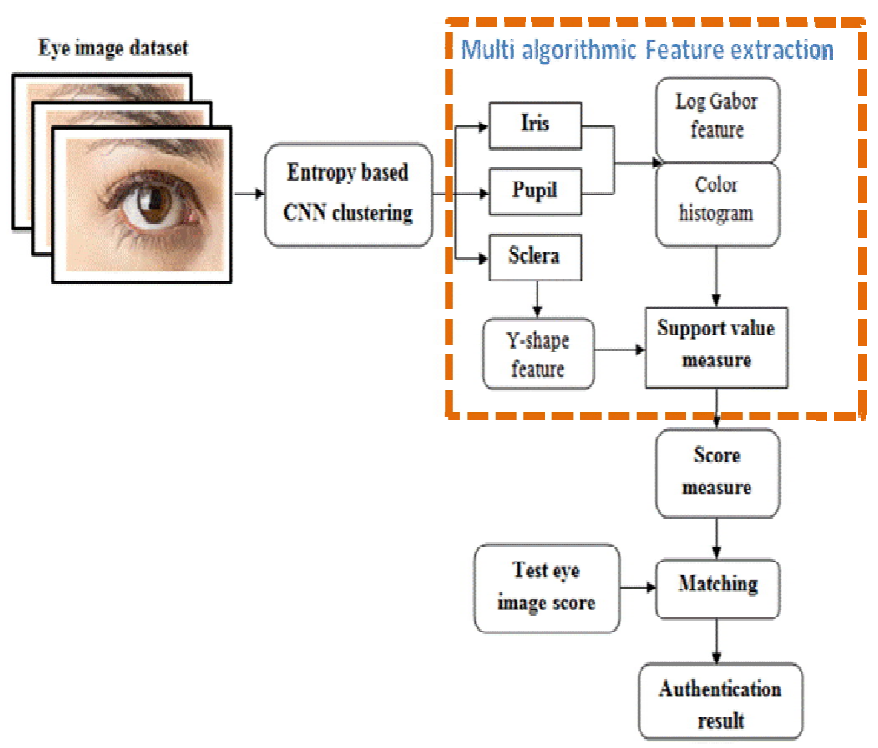

Figure 1: Proposed multimodal eye biometric system [21].

\subsection{Entropy based CNN Segmentation}

The purpose of segmentation in image processing is to identify the region of interest. Precise segmentation of image is necessary otherwise incorrect segmentation will results in poor performance of recognition [22]. In proposed system, entropy is derived from contour based color, texture and brightness features. Convolutional neural network is used to cluster iris, sclera and pupil region based on similarity obtained by entropy measures.

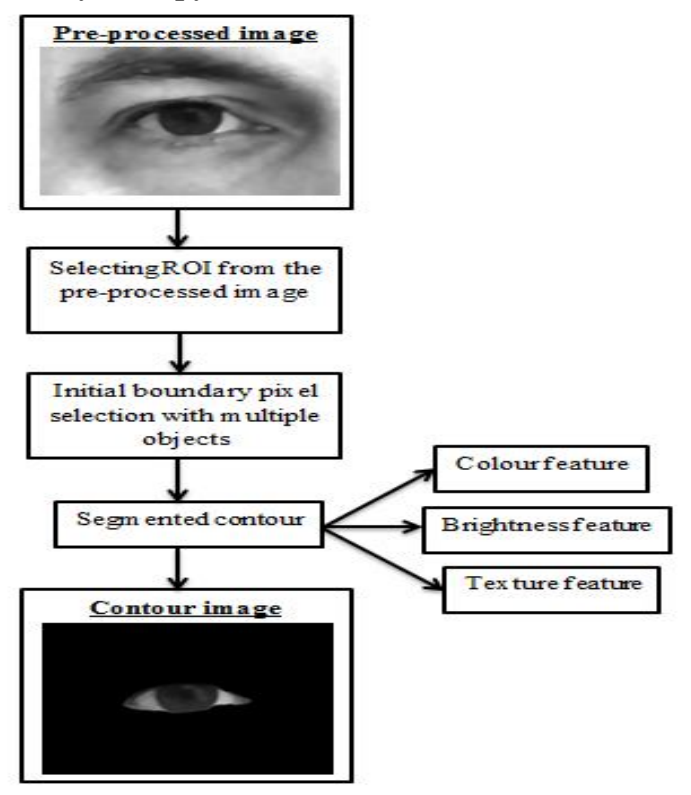

Figure 2: contour based feature extraction

\section{Contour feature extraction}

Contour represents characteristics of visual pattern available in image which are derived based on color, texture and brightness features. Therefore contours represent the subset of features which helps to perform segmentation accurately with less number of features [23]. The proposed contour based feature extraction is shown in figure 2 .

Texture value of local region surrounding the pixel is estimated by comparing the texton distribution on either side of pixel relative to its dominant orientation. Value of texture lies between 0 and 1 . The objects in image which are silent in color are may be black or white describe the characteristics of brightness. Brightness can be measured by comparing the intensity value of a pixel with its neighbor. For constant image, brightness value is zero. Color features are most widely used attribute to represent characteristics of image[24]. Color features are estimated based on occurrences of every color indexes in an image with dissimilar intensities.

\section{Entropy Features Extraction}

Entropy is a measurement of the degree of uncertainty that exists in a system. Shannon's entropy is an important measure for evaluating structures and patterns in the data which can be used to characterized texture in the image. The entropy is extracted for the effective segmentation of iris pupil and sclera regions. In proposed system this entropy values are calculated to distinguish iris, sclera and pupil region based on available texture in contour image [9],[23]. Entropy of the $i^{i^{\text {th }}}$ super pixel $E_{y}^{i}$ is computed using following the equation.

$E_{y}^{i}=\sum_{i=0}^{m-1} \sum_{j=0}^{m-1} P(i, j)\left(-\log _{2}(P(i, j))\right)$

For $\mathrm{N}$ dimensional co-occurrences matrix, $\mathrm{P}(\mathrm{i}, \mathrm{j})$ represent elements in matrix at coordinates $(\mathrm{i}, \mathrm{j})$

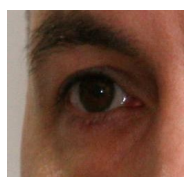

Input

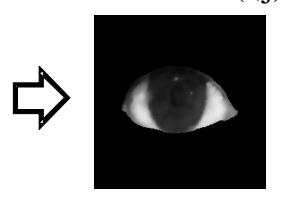

Contour Image

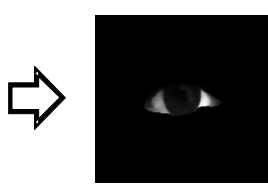

Entropy image
Figure 3: entropy image formation from contour image

\section{Deep learning based image segmentation}

We proposed deep learning based clustering approach to segment iris, sclera and pupil region by passing the entropy image through convolution neural network $(\mathrm{CNN})$ which trends to extract global features available from image. $\mathrm{CNN}$ is 
one the variation of feed forward artificial neural network which is composed of with multiple hidden layers. Commonly CNN is composed of three basic layers: convolution layers, pooling layers and fully connected layers [25][31].

In convolution layers filters are applied on input image to generate the feature map. Each Convolutional layer consist of multiple series of filters known as kernel. In proposed system $5 \mathrm{X} 5$ filter size is used at each convolution layer to extract the local features which is referred as weight sharing. After convolution operation, a non linear activation function Rectified Linear Unit (ReLU) is applied to the output of convolution layer to accelerate the convergence of CNN. We proposed Cuckoo search method to update the value of weight and bios at each layer[29]. Next layer, pooling layer also known as down sampling layer is applied on output of convolution layer to reduce the dimensions and number of parameters of CNN. The Max-pooling layer is used to perform the local max operation over the input features using 2X2 filter size to reduce the parameters and obtain local invariant features. Fully connected layers takes output of last pooling layer as an input to flattened into a single vector of values, each representing a probability that a certain feature belongs to a either iris, sclera or pupil region after applying the softmax function [ 9],[23]. Detail structure of convolutional neural network used in proposed system is described by figure 4 .

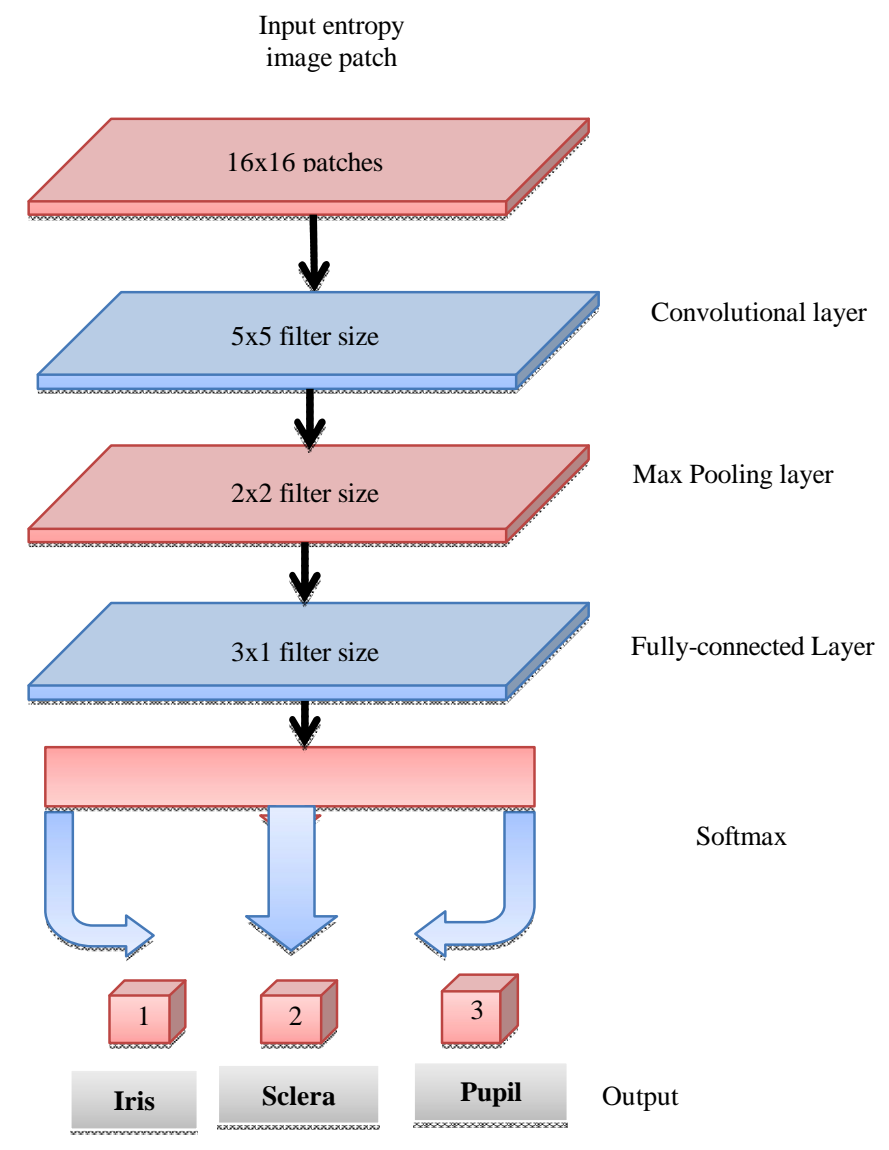

Figure 4: Structure of Convolution Neural Network

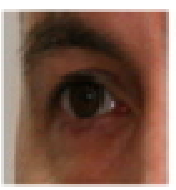

Input image

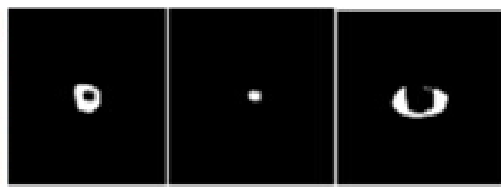

Iris

Pupil

Sclera
Figure 4: segmentation of iris, pupil and sclera

\subsection{Feature extraction}

In eye biometric system color, texture and shape are the prominent and reliable features for iris, sclera and pupil which can be used generate the feature vector for correct authentication. In proposed system we extract the color and texture information from segmented iris and pupil region which is combined with the Y-shaped features extracted from sclera. Color histogram algorithm is used extract the color features where as log Gabor filter is used to extract the texture features. Sclera of human eye is compromised with different layers [26] which form the stable blood vessel pattern which is unique for every person. These blood vessels forms Y shaped branches which are stable used to calculate sclera descriptor value. In proposed system to find out Y-shape features $\left(S_{\text {shape }}\right)$, we look for nearest set of neighbors in all line segments at regular distance and classify the angles between these neighbors to derive structure [27].

\subsection{Feature level fusion}

We proposed the feature level fusion of feature extracted from iris, sclera and pupil biometric trait. These features are taken together to calculate joint feature vector known as support value [9].

$$
\tilde{S}_{\text {value }}=\left(G^{\prime}(f)+R^{\prime}+D_{L C H}^{\prime}\left(I^{\prime}\right)\right) / G^{\prime}(f) * R^{\prime} * D_{L C H}^{\prime}\left(I^{\prime}\right)
$$

Where, $G^{\prime}(f)$ is the $\log$ Gabor feature, $R^{\prime}$ is the sclera

Y-shaped feature, $D_{L C H}^{\prime}\left(I^{\prime}\right)$ is the color histogram feature.

The score measure dependent on the support value, minimum and the maximum value of all features is portrayed as,

$$
\begin{aligned}
& S^{\prime}=\tilde{S}_{\text {value }}+W_{\max }+W_{\min } \\
& W_{\max }=\max \{\text { all features }\} \\
& W_{\min }=\min \{\text { all features }\}
\end{aligned}
$$

\subsection{Matching}

We use the Euclidean distance method to compare the support match score value of test data with estimated values stored in trained enrollment database. Euclidean distance is applied for pixel wise comparison of images. If the calculated distance is lesser than threshold value then data classified as recognized otherwise it is rejected. 


\section{RESULT AND DISCUSSION}

The proposed eye biometric system is implemented on working platform MATLAB. Experimentations are performed on freely available research database MMU and UBIRIS.v2. MMU database contains the 450 images acquired with the help of dedicated semi automated camera (LG Iris Access) from distance $7-25 \mathrm{~cm}$. For unconstrained or relaxed color eye images we used UBIRIS.v2 database which contains 11102 images acquired at different session from distance 4- 8 meters with the help of Canon EOS 5D. It represent 14 different type of noise such as motion blur, off angle, poorly focused, obstruction of eye lashes glass, hair, etc. 300 and 2000 images from MMU and UBIRIS.v2 are used respectively for training and testing purposes in ratio 80:10.

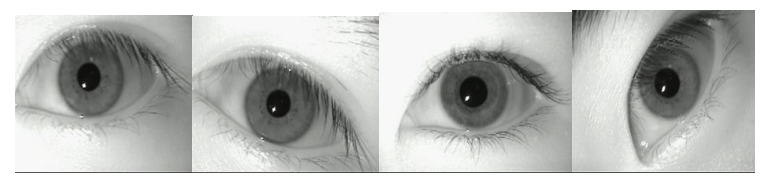

Figure 5: sample images for MMU database

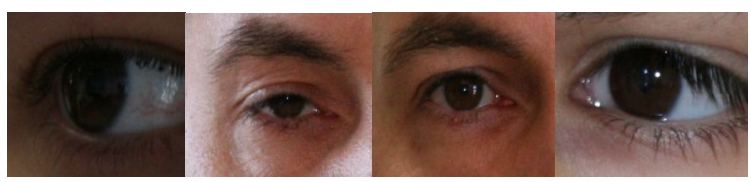

Figure 6: sample images for UBIRIS.v2 database

Performance of segmentation is analyzed for proposed entropy feature based deep learning segmentation method using CNN. From contour image generated based on the color, texture and brightness features, we calculate the entropy value which minimize the feature set by avoiding the redundant and poor quality features. This helps to reduce the computational complexity as well as time required for segmentation.

Table 2: Entropy values for MMU database images

\begin{tabular}{|c|l|c|}
\hline Labeled images & Entropy value & $\begin{array}{c}\text { Classification } \\
\text { Accuracy }\end{array}$ \\
\hline & 10.84560658 & 88.74 \\
\hline & 12.91781241 & 100 \\
\hline & 13.18990281 & 100 \\
\hline & 13.36857564 & 94 \\
\hline & 13.72492633 & 98.3 \\
\hline & 13.84040755 & 100 \\
\hline
\end{tabular}

\begin{tabular}{|c|l|c|}
\hline$(3)$ & 13.87388653 & 100 \\
\hline$(6)$ & 11.03423424 & 92.4 \\
\hline & 11.3308829 & 100 \\
\hline & 11.4825514 & 95.9 \\
\hline
\end{tabular}

Table 3: Entropy values for UBIRIS.v2 Database images

\begin{tabular}{|c|c|c|}
\hline Labeled images & Entropy value & $\begin{array}{c}\text { Classification } \\
\text { accuracy }\end{array}$ \\
\hline & 10.84951952 & 94.3 \\
\hline & 12.00494672 & 100 \\
\hline & 14.08889121 & 100 \\
\hline & 14.22193309 & 100 \\
\hline & 13.4799699 & 100 \\
\hline & 13.41671058 & 100 \\
\hline & 11.16364744 & 100 \\
\hline & 11.32630209 & 99 \\
\hline & & 98.64 \\
\hline
\end{tabular}

From table 2 and table 3 , we observed that if the entropy value is increased then classification accuracy for iris, sclera and pupil region using CNN is also improved for MMU and UBIRIS.v2 database images We able to achieve classification accuracy up to $100 \%$ for image entropy values lies between 13-14. If we compare the images from MMU and UBIRIS.v2 database, Entropy value for gray images are less as compared to entropy values estimated for color eye images due to availability of less number of color and texture feature in input eye images.

Accuracy of iris, sclera and pupil segmentation is enhanced by using proposed segmentation algorithm for images taken for UBIRIS.v2 database as compared to MMU database images prominent large number of visible colour and texture features. Performance comparison of segmentation results for MMU and UBIRIS.v2 database is given in table 4. 
Table 4: Performance of segmentation of iris, sclera and pupil region based MMU and UBIRIS.v2 database [9]

\begin{tabular}{|l|l|l|l|l|l|}
\hline $\begin{array}{c}\text { Biometric } \\
\text { Trait }\end{array}$ & Database & Accuracy & $\begin{array}{l}\text { Positive } \\
\text { Predictive } \\
\text { value } \\
\text { (PPR) }\end{array}$ & $\begin{array}{l}\text { False } \\
\text { Negative } \\
\text { Rate } \\
\text { (FNR) }\end{array}$ & $\begin{array}{l}\text { False } \\
\text { Detectio } \\
\text { n Rate } \\
\text { (FDR) }\end{array}$ \\
\hline \multirow{2}{*}{ Iris } & MMU & 97.15 & 97.43 & 0.31 & 2.57 \\
\cline { 2 - 6 } & UBIRIS.v2 & 97.99 & 99.84 & 1.89 & 0.16 \\
\hline \multirow{2}{*}{ Sclera } & MMU & 95.54 & 96.26 & 0.79 & 3.74 \\
\cline { 2 - 6 } & UBIRIS.v2 & 98.08 & 98.38 & 0.34 & 1.62 \\
\hline \multirow{3}{*}{ Pupil } & MMU & 98.28 & 98.31 & 0.04 & 1.69 \\
\cline { 2 - 6 } & UBIRIS.v2 & 99.42 & 91.42 & 0.70 & 8.58 \\
\hline
\end{tabular}

It is difficult to extract the Y-count sclera feature for gray or black and white images as compared to color images because of their appearance. Therefore from table 5 and table 6 , we can say that value of sclera Y-count features decreases for gray images compared to color images. This results in performance of recognition accuracy. Recognition accuracy of eye biometric system is increases if the value of sclera $\mathrm{Y}$ count is good.

Table 5: Feature and Support values for MMU Database images

\begin{tabular}{|c|c|c|c|c|c|c|c|c|}
\hline \multirow{3}{*}{$\begin{array}{c}\text { Labeled } \\
\text { images }\end{array}$} & \multicolumn{5}{|c|}{ Feature values } & \multirow{3}{*}{$\begin{array}{l}\text { Support } \\
\text { value }\end{array}$} & \multirow{3}{*}{$\begin{array}{c}\text { Classification } \\
\text { Accuracy }\end{array}$} & \multirow{3}{*}{$\begin{array}{c}\text { Recognition } \\
\text { Accuracy }\end{array}$} \\
\hline & \multicolumn{2}{|l|}{ Iris } & \multicolumn{2}{|l|}{ pupil } & \multirow{2}{*}{$\begin{array}{c}\text { Sclera } \\
\text { Y-count }\end{array}$} & & & \\
\hline & himax & gimax & hpmax & gpmax & & & & \\
\hline & 64464 & $2.95 \mathrm{E}-14$ & 65264 & $2.63 \mathrm{E}-14$ & 20 & $1.45 \mathrm{E}+24$ & 88.74 & 89 \\
\hline & 64161 & $3.00 \mathrm{E}-14$ & 65341 & $2.34 \mathrm{E}-14$ & 67 & $1.74 \mathrm{E}+23$ & 100 & 100 \\
\hline & 64146 & $1.91 \mathrm{E}-14$ & 65120 & $3.15 \mathrm{E}-14$ & 127 & $2.12 \mathrm{E}+22$ & 100 & 100 \\
\hline & 63827 & $2.46 \mathrm{E}-14$ & 65087 & $2.80 \mathrm{E}-14$ & 230 & $3.75 \mathrm{E}+22$ & 94 & 94 \\
\hline & 64040 & $2.28 \mathrm{E}-14$ & 63912 & $3.50 \mathrm{E}-14$ & 253 & $5.49 \mathrm{E}+23$ & 98.3 & 97.6 \\
\hline & 64096 & $2.76 \mathrm{E}-14$ & 61656 & $2.71 \mathrm{E}-14$ & 271 & 4.17E+22 & 100 & 100 \\
\hline & 63883 & $2.66 \mathrm{E}-14$ & 62769 & $3.27 \mathrm{E}-14$ & 358 & $6.70 \mathrm{E}+21$ & 100 & 100 \\
\hline & 64140 & $2.80 \mathrm{E}-14$ & 65450 & $2.94 \mathrm{E}-14$ & 60 & $2.62 \mathrm{E}+23$ & 92.4 & 91.7 \\
\hline & 64160 & $3.24 \mathrm{E}-14$ & 65358 & $3.39 \mathrm{E}-14$ & 87 & $3.02 \mathrm{E}+22$ & 100 & 100 \\
\hline$x$ & 64501 & $2.54 \mathrm{E}-14$ & 65466 & $2.31 \mathrm{E}-14$ & 97 & $3.61 \mathrm{E}+22$ & 95.9 & 96.1 \\
\hline
\end{tabular}

Table 6: Feature and Support values for UBIRIS.v2 Database images

\begin{tabular}{|c|c|c|c|c|c|c|c|c|}
\hline \multirow{3}{*}{$\begin{array}{l}\text { Labeled } \\
\text { images }\end{array}$} & \multicolumn{5}{|c|}{ Feature values } & \multirow{3}{*}{ Support value } & \multirow{3}{*}{$\begin{array}{l}\text { Classificatio } \\
\text { n Accuracy }\end{array}$} & \multirow{3}{*}{$\begin{array}{l}\text { Recognition } \\
\text { Accuracy }\end{array}$} \\
\hline & \multicolumn{2}{|c|}{ Iris } & \multicolumn{2}{|c|}{ pupil } & \multirow{2}{*}{$\begin{array}{l}\text { Sclera } \\
\text { Y- count } \\
\end{array}$} & & & \\
\hline & himax & $\operatorname{gimax}$ & hpmax & gpmax & & & & \\
\hline & 65244 & $2.53 \mathrm{E}-14$ & 63621 & $2.58 \mathrm{E}-14$ & 75 & $1.90 \mathrm{E}+23$ & 94.33 & 97.6 \\
\hline & 64884 & $2.40 \mathrm{E}-14$ & 59448 & $3.41 \mathrm{E}-14$ & 165 & $1.75 \mathrm{E}+23$ & 100 & 100 \\
\hline & 64900 & $2.33 \mathrm{E}-14$ & 58528 & 4.16E-14 & 237 & $2.02 \mathrm{E}+22$ & 100 & 100 \\
\hline - & 64981 & $2.13 \mathrm{E}-14$ & 58502 & $4.30 \mathrm{E}-14$ & 310 & $1.60 \mathrm{E}+23$ & 100 & 100 \\
\hline & 64706 & $2.30 \mathrm{E}-14$ & 55567 & $2.70 \mathrm{E}-14$ & 314 & $2.19 \mathrm{E}+23$ & 100 & 100 \\
\hline & 63859 & $2.52 \mathrm{E}-14$ & 56732 & $3.07 \mathrm{E}-14$ & 425 & $3.46 \mathrm{E}+22$ & 100 & 100 \\
\hline$(19)$ & 64245 & $3.27 \mathrm{E}-14$ & 56682 & $3.78 \mathrm{E}-14$ & 428 & $1.41 \mathrm{E}+22$ & 100 & 100 \\
\hline 230 & 65198 & $2.74 \mathrm{E}-14$ & 63567 & $3.31 \mathrm{E}-14$ & 111 & $3.42 \mathrm{E}+22$ & 99 & 99 \\
\hline$\infty$ & 65257 & $2.38 \mathrm{E}-14$ & 63139 & $2.90 \mathrm{E}-14$ & 116 & $7.33 \mathrm{E}+22$ & 98.64 & 99.2 \\
\hline es & 65155 & $1.79 \mathrm{E}-14$ & 63773 & $3.26 \mathrm{E}-14$ & 118 & $1.26 \mathrm{E}+23$ & 100 & 100 \\
\hline
\end{tabular}


From table 7 , we can say that the eye biometric system recognition performance is improved for the feature level fusion as compared to score level fusion because of availability of large number of features [29-30] for feature vector generation which is used for matching with template stored in trained database. reducing time required for segmentation up to $0.9 \mathrm{sec}$ for noisy color eye images.

Table 7: Performance analysis for eye biometric recognition system based on level of fusion

\begin{tabular}{|c|c|c|c|c|}
\hline Author & $\begin{array}{l}\text { Modality } \\
\text { Fusion }\end{array}$ & Fusion Technique & Database & $\begin{array}{l}\text { Result } \\
\text { (EER \%) }\end{array}$ \\
\hline Zhou et al. & Iris and sclera & Score level fusion & UBIRIS V1 & $2.73 \%-3.06 \%$ \\
\hline $\begin{array}{l}\text { Gottemukkula } \\
\text { et al. }\end{array}$ & Iris and sclera & $\begin{array}{l}\text { Weighted score } \\
\text { fusion }\end{array}$ & $\begin{array}{l}\text { In House (Constrained } \\
\text { Images) }\end{array}$ & $2.39 \%$ \\
\hline Zhou et al. & Iris and sclera & Score level fusion & $\begin{array}{l}\text { IUPUI green-wavelength } \\
\text { database }\end{array}$ & $0.63 \%$ \\
\hline $\begin{array}{l}\text { Jibu Varghese } \\
\text { K. et.al. }\end{array}$ & Iris and Sclera & $\begin{array}{l}\text { No Fusion } \\
\text { Simultaneous }\end{array}$ & $\begin{array}{l}\text { In House database only } \\
\text { high qualitv images used }\end{array}$ & Accuracy $-99.4 \%$ \\
\hline $\begin{array}{l}\text { C. Immaculate } \\
\text { Mary }\end{array}$ & Iris and sclera & $\begin{array}{l}\text { Inter-Fusion using } \\
\text { Laplace Transform }\end{array}$ & $\begin{array}{l}\text { Quality_Face/Iris } \\
\text { Research } \quad \text { Ensemble }\end{array}$ & Accuracy $=85 \%$ \\
\hline $\begin{array}{l}\text { Nassima Kihal } \\
\text { et.al }\end{array}$ & $\begin{array}{l}\text { Iris and corneal } \\
\text { shape }\end{array}$ & Match score & $\begin{array}{l}\text { In-house } \\
\text { (Constrained }\end{array}$ & $0.09 \%$ \\
\hline $\begin{array}{l}\text { Abhijit Das et. } \\
\text { al }\end{array}$ & $\begin{array}{l}\text { Iris, sclera and } \\
\text { peri-ocular }\end{array}$ & Decision level & $\begin{array}{l}\text { Multi angle sclera } \\
\text { database(MASD) }\end{array}$ & $\begin{array}{l}\text { Iris+sclera }=> \\
\text { Accuracy }=91.78 \\
\text { Iris+sclera+periocular=> } \\
\text { Accuracy }=96.53 \%\end{array}$ \\
\hline $\begin{array}{l}\text { M.K.Pathak } \\
\text { et.al }\end{array}$ & $\begin{array}{l}\text { Iris, sclera } \\
\text { and pupil }\end{array}$ & $\begin{array}{l}\text { Feature } \\
\text { fusion }\end{array}$ & MMU and UBIRIS.v2 & $\begin{array}{l}\text { Accuracy for } \\
=93.33 \% \\
\text { UBIRIS.v2=97.99\% }\end{array}$ \\
\hline
\end{tabular}

From table 7, we can say that the eye biometric system recognition performance is improved for the feature level fusion as compared to score level fusion because of availability of large number of features [29,30] for feature vector generation which is used for matching with template stored in trained database.

\section{CONCLUSION}

Present standalone biometric systems are not $100 \%$ reliable, they also suffer from spoofing attacks due to lack of invariant representation and noisy input. Therefore multiple biometric cues are combined together to achieve better performance of biometric authentication. Proposed eye biometric system combines the prominent features of iris, sclera and pupil to improve the accuracy of recognition for the images acquired in unconstrained or relaxed environment. Entropy based feature selection proves that it reduces time required for segmentation because of selection of optimal set of feature selection. Classification accuracy is increases with increase in entropy values for input image. From results proposed system also represent that for greater count of Y-sclera features, accuracy of eye biometric system also improved. Overall multimodal eye biometric system recognition performance with respect to accuracy, PPV, GAR, etc. is improved by

\section{REFERENCES}

1. A. k. Jain, A. Ross and S. Prabhakar. An Introduction to Biometric Recognition, IEEE Trans. on Circuits and Systems for Video Technology, vol. 14, no. 1, pp. 4-19, 2004.

2. A. K. Jain and A. Kumar. Biometrics of Next Generation: An Overview, The International Library of Ethics, Law and Technology, vol 11. Springer, Dordrecht, ELTE, March 2012, vol. 11, pp.49-79.

H. Jaafar and D. A. Ramli. A Review of Multibiometric System with Fusion Strategies and Weighting Factor, International Journal of Computer Science Engineering (IJCSE), vol.2, pp. 158-165, 2013.

3. M. O. Oloyede and G. P. Hancke. Unimodal and Multimodal Biometric Sensing Systems: A Review, IEEE Access, 2016, DOI 10.1109/ACCESS.2016. 2614720.

4. P. Aparna and P. V. V. Kishore. Biometric-based efficient medical image watermarking in E-healthcare application, IET Image Processing, vol. 13, no. 3, pp. 421-428, Feb. 2019.

5. W. Dahea. Multimodal biometric system: A review, International Journal of Engineering and Technology, Vol. 4, no. 1, pp. 25-31, Jan. 2018.

6. N. U. Ahmed, S. Cetkovic, E. H. Siddiqi, A. Nikiforov and I. Nikiforov. Combining iris and periocular 
biometric for matching visible spectrum eye images, Pattern Recognition Letters, Vol. 91, pp. 11-16, 2017.

7. M. K. Pathak, N. Srinivasu and V. K. Bairagi. Effective segmentation of sclera, iris and pupil in noisy eye images, TELKOMNIKA, Vol. 17, No. 5, pp. 2346-2354, Oct. 2019,

8. M. K. Pathak, N. Srinivasu and V. K. Bairagi. Support Value Based Fusion Matching Using Iris and Sclera Features for Person Authentication in Unconstrained Environment, Journal of Engineering Science and Technology, Vol. 15, No. 4, Aug. 2020.

9. I. Nigam, M. Vatsa and R. Singh, Ocular biometrics: A survey of modalities and fusion approaches, Information Fusion, vol. 26, pp. 1-35, 2015.

10. Z. Zhou, E. Y. Du, Y. Lin, N. L. Thomas, C. Belcher, and E. J. Delp. Feature Quality-based Multimodal Unconstrained Eye Recognition, Proceedings of SPIE The International Society for Optical Engineering ,2013, $875587550 \mathrm{~J}-2$.

11. V. Gottemukkula, S. K. Saripalle,R. Pasula and A. Ross. Fusing Iris and Conjunctival Vasculature: Ocular Biometrics in the Visible Spectrum. Proc. of IEEE International Conference on Technologies for Homeland Security (HST), Waltham, USA, Nov. 2012, pp.150-155.

12. C. Tan and A. Kumar. Towards Online Iris and Periocular Recognition under Relaxed Imaging Constraints, IEEE Transactions on Image Processing, vol. 22, no. 10 , pp. 3751 - 3765 , Oct. 2013.

13. J. K. Varghese, T. Singh, R. Pradeep , V. Bichu , A. Anand and R. Mithun. Development Of A Dual Authentication System Using Iris And Sclera Features, International Journal of Industrial Electronics and Electrical Engineering, vol. 2, no. 11, Nov.2014.

14. C. I. Mary. Inter-Fusion of Iris and Sclera Surface Patterns: Biometric Recognition Using the Laplace Transform, International Journal of Advanced Research in Computer Science and Software Engineering, vol. 4, no. 11, pp. 196-204, Nov. 2014.

15. G. Santos , E. Grancho, M. V. Bernardo and P. T. Fiadeiro. Fusing iris and periocular information for cross-sensor recognition, Pattern Recognition Letters, vol.57, pp.52-59, 2015.

16. N. Kihal, S. Chitroub, A. Polette, I. Brunette and Jean Meunier. Efficient multimodal ocular biometric system for person authentication based on iris texture and corneal shape, IET Biometrics, Vol. 6, no. 6, pp. 379-386, 2017.

17. M.K. Pathak, V. K. Bairagi and N. Srinivasu. Match Score Level Fusion of Iris and Sclera Descriptor for Iris Recognition, IEEE International Conference on Soft Computing and its Engineering Applications (icSoftComp-2017), ISBN: 978-93-5268-320-8.

18. N. U. Ahmed, S. Cvetkovic, E. H. Siddiqi, A. Nikiforov and I. Nikiforov, Combining iris and periocular biometric for matching visible spectrum eye images, Pattern Recognition Letters, vol.91, pp. 11-16, 2017.

19. Z. Wang, C. Li, H. Shao and J. Sun, Eye Recognition with Mixed Convolutional and Residual Network(MiCoRe-Net),IEEE Access, vol. 14, no. 8, pp.1-8, Aug. 2015.

20. M.K. Pathak, V. K. Bairagi and N. Srinivasu. Multimodal Eye Biometric System Based on Contour Based E-CNN and Multi Algorithmic Feature Extraction Using SVBF Matching, I International Journal of Innovative Technology and Exploring Engineering (IJITEE), vol. 8, no. 9, pp. 418-423, July 2019.

21. R. Sunitha, S. Maloji, P. V. V. Kishore, Kumar, K. E Kumar, K. M. Teja and A. D. Kumar. Multi modal spatio temporal co-trained CNNs with single modal testing on RGB-D based sign language gesture recognition, Journal of computer languages, vol. 52, pp. 88-102, June 2019.

22. M.K. Pathak, V. K. Bairagi and N. Srinivasu. Entropy Based CNN for Segmentation of Noisy Color Eye Images using Color, Texture and Brightness Contour Features, International Journal of Recent Technology and Engineering (IJRTE), vol. 8, no. 2, pp. 2116-2124, July 2019.

23. L. K. Rao, R. Pinapatruni and L. P. Reddy. Local color oppugnant quantized extrema patterns for image retrieval, Multidimensional Systems And Signal Processing, July 2019, https://doi.org/10.1186/ s40064 -016-2664-9.

24. E. K. Kumar, P. V. V. Kishore, A. S. C. S. Sastry, M. T. K. Kumar and D. A. Kumar, Training CNNs for 3-D Sign Language Recognition With Color Texture Coded Joint Angular Displacement Maps, IEEE Signal Processing Letters, vol. 25 , no. 5, May 2018.

25. S. Alkassar, W. L. Woo, S. Dlay and Jonathon Chambers, Sclera recognition: on the quality measure and segmentation of degraded images captured under relaxed imaging conditions, IET Biometric, 2017, vol. 6 no. 4, pp. 266-275.

26. Y. Lin, E. Y. Du, Z. Zhou and N. L. Thomas. An efficient parallel approach for Sclera vein recognition, IEEE Transactions, Information Forensics And Security, Vol. 9, No. 2, pp. 147-157, Feb. 2014.

27. K. Thirugnanasambandam, S. Prakash, V. Subramanian, S. Pothula and V. Thirumal, V. Reinforced cuckoo search algorithm-based multimodal optimization, Applied Intelligence, vol. 49, pp. 2059-2083, June2019

28. I. Nigam, M. Vatsa and R.Singh, Ocular biometrics: A survey of modalities and fusion approaches, Information Fusion, vol. 26, pp. 1-35, 2015.

29. M. K. Pathak and N. Srinivasu. Analysis of Multimodal Biometric System Based on Level of Fusion, International Journal of Inventive Engineering and Sciences (IJIES), vol. 3, no. 8, pp. 8-11, July 2015.

30. A. Hussein, F. K. Ahmad and S. S. Kamaruddin. Content-Social Based Features for Fake News 
Detection Model from Twitter, International Journal of Advanced Trends in Computer Science and Engineering, vol.8, no. 9, pp. 2806-2810, Dec 2019.

31. N. Manikandan, M. Priyanka, Sasikumar and R. Muthaiah. Approximation Computing Techniques to Accelerate CNN Based Image Processing Applications - A Survey in Hardware/Software Perspective. International Journal of Advanced Trends in Computer Science and Engineering, vol.9, no. 3, pp. 3828-3846, June 2020. 